\title{
Developing Information Technology Fluency in College Students: An Investigation of Learning Environments and Learner Characteristics
}

\author{
Nancy B. Sardone \\ Georgian Court University, Lakewood, NJ, USA
}

nsardone@georgian.edu

Executive Summary

The confluence of powerful technologies of computers and network connectivity has brought explosive growth to the field of Information Technology (IT). The problem presented in this study is whether the type of learning environment where IT concepts are taught to undergraduates has a relationship to the development of IT fluency and course satisfaction. The literature suggested that, if learning environments based on constructivist learning strategies were used, students would achieve IT fluency as well as those who studied in a traditional setting but they might be more satisfied.

This paper is organized as follows. First, the problem is introduced followed by a review of the definition of IT fluency, then the paper moves to discuss learning environments and other associated factors relevant to this causal-comparative analysis. Next, the research design of the study is discussed, to include the four modes of inquiry used and the research questions that guided inquiry. A detailed data analysis follows, findings are presented, and the conclusion highlights findings. Recommendations are geared to instructors in higher education business/technology programs interested in designing instruction in conjunction with constructivist learning environments.

Keywords: college students, constructivism, information technology fluency, learning environments, learning styles

\section{Introduction}

The definition of information technology (IT) fluency has evolved over the past 25 years and continues to evolve, as we become a society increasingly dependent on information technology. Years ago, IT fluency was associated with the ability to write a computer program using COBOL or Assembly Language (Bartholomew, 2004) often in pursuit of a computer science degree. In 1983, with Microsoft's announcement of their Windows ${ }^{\circledR}$ operating system and graphical user interface, the definition of IT fluency became synonymous with software-skills ability (Computer

Material published as part of this publication, either on-line or in print, is copyrighted by the Informing Science Institute. Permission to make digital or paper copy of part or all of these works for personal or classroom use is granted without fee provided that the copies are not made or distributed for profit or commercial advantage AND that copies 1) bear this notice in full and 2) give the full citation on the first page. It is permissible to abstract these works so long as credit is given. To copy in all other cases or to republish or to post on a server or to redistribute to lists requires specific permission and payment of a fee. Contact HPublisher@InformingScience.orgH to request redistribution permission.
Science and Telecommunications Board, 1999; Microsoft, 2005). While the demands associated with IT knowledge that are placed on college graduates are greater than they were even five years ago (Terrell, 2007), many in business technology programs in higher education still continue to define IT fluency as the ability to use computer software (Kaminski, Switzer, \& Gloeckner, 2009; Kesten \& Lambrecht, 2010). Ac-

Editor: Thomas Connolly 
cording to Kesten \& Lambrecht (2010), part of the issue is that information technology as a field of study is not unique to business and requires preparation at a variety of levels. Kaminski et al. (2009) point out that a software-skills approach to IT fluency is too slim of an approach and students do not retain software skill knowledge and/or sequential processes when the IT curriculum is so narrowly defined. Earlier studies echo these findings (Bartholomew, 2004; Chen \& Ray, 2004).

Organizations need individuals with higher-order IT competencies since they depend on IT as a conduit to innovation, transformation, and competition in a global society (Friedman, 2005; Gilpin, 2001; Moncarz, 2002; Terrell, 2007). "The preparedness and skill levels of its workforce are critical factors in the ability of the United States to stay competitive in the 21 st century" (Klein, Cavanagh, Kay, \& Meisinger, 2006, p. 12). As such, higher education needs to do a better job of equipping students as productive and knowledgeable technology workers, not only when entering the labor market, but to provide adaptability within the labor market (U. S. Department of Labor, 1999).

Perhaps the lack of shared understanding of what it means to be IT fluent has limited IT course curriculum development in higher education. A revised and more current definition still encompasses software proficiency, but expands it to include demonstrated knowledge of computer operations, networks, online resources, digital media, and programming (National Research Council [NRC], 1999; Snyder, 2003). IT competency continues to rank among the top applied skills sought in entry-level workers (Klein et al., 2006; Zhao \& Alexander, 2002) as rapid technology deployment and dependency continues to drive up the worldwide need for a skilled workforce. Individuals possessing high-level IT skills and conceptual knowledge are favored in the hiring process as their ability to learn new technologies lessens the amount of training they will need (Klein et al., 2006; Zhao \& Alexander, 2002). Armed with such competencies, workers would be able to grow their IT skills and knowledge over time while remaining an asset to their organization.

\section{Literature Review}

\section{IT Fluency}

An understanding that focuses on learning to learn IT is in stark contrast to a software skills approach to IT fluency, which focuses on usage of technology's tools. Studies that suggest software use represents IT fluency can result in false assumptions. Current studies evaluating the responses of Generation Y indicate that they are a powerful demographic group described as in a hurry to use grown up tools such as computers, software, and the Internet (Montgomery, 2007). They have become highly effective at influencing their families' consumer decisions, partly due to the shift from authoritarian to more permissive parenting styles. The Kaiser Family Foundation (2009) examines media usage among a nationally representative sample of youths, reporting that children ages 8 to 18 are exposed to almost 11 hours of media in a typical day, including more than four hours spent watching television content. A large survey reported by Speak Up (2009) found youth are innovative users of technology and ultra-communicators, learn technology tasks at home with family support, demand up-to-date technology tools at school, and are frustrated with their teachers' lack of technology innovativeness. The Pew Internet \& American Life Project indicates that 76 percent of respondents, ages 18-29, use the Internet for school research, followed by games, email, and instant messaging (Fox, Anderson, \& Rainie, 2005). The EduCause Center for Applied Research (ECAR) surveyed 27,846 undergraduates from 103 higher education institutions and reported they used their computer for an average of 18 hours per week to conduct school, work, and recreational activities (Borrenson-Caruso \& Salaway, 2007). 
Yet, under the revised IT fluency definition, current college students' conceptual knowledge of computer technology is in question. Three studies provide evidence of conceptual knowledge deficiencies among college students. Northwest Missouri State University reported that of the 191 students who took an IT proficiency exam, only two percent mastered it at an 80 percent rate (Hardy, Heeler, \& Brooks, 2006). At a large Midwestern university, results reveal that students' $(\mathrm{n}=91)$ perception of their IT fluency is far greater than actually realized (Wilkerson, 2006).

Quinnipiac University freshmen $(n=800)$ report they learned technology tasks at home with family support, concluding that familial education may equip students to accomplish immediate goals, but it may not be sufficient to be successful in college and beyond (Hoffman \& Vance, 2004). Based on their ability to influence their families' consumer decisions regarding IT tools, demand for up-to-date technology tools, and desire to be taught using innovative techniques involving technology, one could conclude that the 1.7 million high school graduates who enroll in college every year come to the institution prepared with the technical skills, concepts, and capabilities needed for success in college and beyond (Blymier, Rockman, \& Williamson, 2005).

However, a huge difference exists between using a computer and understanding how it functions, which is important to the development of the higher-order thinking processes of sustained abstract reasoning and critical thinking needed to become IT fluent (NRC, 1999; Snyder, 2003).

Concepts taught in an IT course under the revised definition include computer organization and hardware, systems software, application software, communications and networks, and the history and social impact of living and working in an IT-based world. Table 1 provides a listing of more detailed topics taught in the course under study.

Table 1. Course Topics

\begin{tabular}{|l|l|}
\hline \multicolumn{1}{|c|}{ General Topic Area } & \multicolumn{1}{c|}{ Specific Topic Area } \\
\hline \hline $\begin{array}{l}\text { Computer Organization and } \\
\text { Hardware }\end{array}$ & $\begin{array}{l}\text { Processing Components, Primary Storage, Pe- } \\
\text { ripherals, Architectures, Data Representation }\end{array}$ \\
\hline Systems Software & Operating Systems, Utilities, User Interfaces \\
\hline \hline Application Software & $\begin{array}{l}\text { Word Processing, Desktop Publishing, Spread- } \\
\text { sheets, Multimedia }\end{array}$ \\
\hline $\begin{array}{l}\text { Communications and Net- } \\
\text { works }\end{array}$ & $\begin{array}{l}\text { World Wide Web, Personal Communications, } \\
\text { Network Access, Network Architecture, Data } \\
\text { Communications }\end{array}$ \\
\hline \hline History and Social Impact & $\begin{array}{l}\text { History, Social Issues, Safety and Security, Ca- } \\
\text { reers }\end{array}$ \\
\hline
\end{tabular}

"Science and math are the universal language of technology however, unless our kids grow up knowing that universal language, they will not be able to compete" in a global context (Friedman, 2005 , p. 272). As a nation, U.S. students continue to rank lower, on average, than their international peers in both math and science, out of 30 developed nations (Cavanagh, 2007). As IT is intertwined with math and science knowledge, the question as to how to effectively develop IT fluency in light of poor math and science skills becomes paramount. The literature suggested that if learning environments based on constructivist learning strategies were used, students would achieve IT fluency as well as those who studied in the traditional environment and course satisfaction would be higher than that of traditionally educated students. Therefore, the purpose of this research study was to examine the relationship between traditional and constructivist learning 
environments to IT fluency and course satisfaction in a course in which students were learning to become IT fluent under the revised definition.

\section{Learning Environment}

The theoretical framework of this study centers on conservative constructivism, the theory of how people learn that considers the engagement of learners in meaningful experiences as the essence of experiential learning (Forcier \& Descy, 2002; D. Kolb, 1985; Wulf, 2005). Constructivist theory was chosen as the framework for this study due to its humanistic, engaging, and reflective tenets that are not commonplace in IT-related courses as they tend to attract students who are more oriented to traditional methods of instruction used in learning computer programming (Kolb, 1985; Lui, Kwan, Poon, \& Cheung, 2004; Naps et al, 2002; Natvig \& Line, 2004; Wulf, 2005).

The term conservative describes the degree of constructivism manifested in the type of instructional methods chosen by the instructor, the frequency of their use, and the assessment of associated products. Constructivist learning theory does not dismiss the active role of the teacher or the value of expert knowledge, nor does it devalue grades. In this study, student products were graded and final course grades awarded.

Constructivism is a recent development in cognitive psychology, influenced by the works of Bruner, Piaget, and Vygotsky (Kauchak \& Eggen, 2003), that shifts learning from a passive transfer of information and collection of facts to active problem-solving and discovery. The type of environment that supports this learning theory is one where the instructor provides interactive, collaborative, and explorative learning activities through which students formulate and test their ideas, draw conclusions and inferences, pool and convey knowledge collaboratively, and it focuses on the central role that learners play in constructing knowledge (Smaldino, Russell, Heinich, \& Molenda, 2005).

In contrast, the transmission model theory of learning suggests that students will learn facts and concepts and come to understand by absorbing the content of their instructors' explanations or by reading content explanations/definitions from a text and answering related questions. In this model, guided repetitive practice in a systematic and highly prescribed fashion through didactic lecture, teacher presentations, and lecture/discussion methods leads the student to mastery (North Central Regional Educational Laboratory, 1995). Most often, lessons taught using the transmission model are intended to direct the predetermined sequence of instruction (Maddux, Johnson, \& Willis, 2001).

The contrast between these two models has a long history in education, stemming from debates about progressive education. Current interest in learning models steeped in constructivist theory can be traced to the public and professional dialogues (Barr \& Tagg, 1995; Cross, 1986) over alternative approaches to education reform that followed the publication of the Nation at Risk report (National Commission on Excellence in Education, 1983). A dynamic shift began to occur in education in the early 1990's with the call for a more literate workforce, able to make critical judgments and decisions. Curricula reformed, creating instruction so that students would be better able to apply critical thinking skills in the study of content areas. In response to the reform, a paradigm shift began to occur in higher education from a focus on providing instruction to a focus on producing learning. As such, materials used and student outcomes from two different learning environments were evaluated in this study - traditional, using a transmission model and constructivist, using an active learning model of education (Ravitz, Becker, \& Wong, 2000).

Studies in IT-related courses evaluating the influence of learning environments on academic achievement report favorable results. Five studies using different research methods were evaluated (survey and correlation, phenomena, observation, content analysis, and experiment) to help 
triangulate the impact of learning environments on academic achievement and satisfaction. The results of these five studies indicate that the better the quality of the student-teacher interactions occurring in a facilitative and constructivist environment, the higher the satisfaction, confidence, and academic achievement of the student (Colbeck, Cabrera, \& Terenzini, 2001; Demetriadis, Triantafillou, \& Pombortsis, 2003; Gonzales, 2006; Lui et al., 2004; Whittington, 2004). However, there remains the possibility that students considered the learning environment and associated methods, which may have influenced learning. In essence, studies leave open the question as to whether variables other than learning environment could affect IT fluency and satisfaction in a given learning environment.

\section{Instructional Methods}

Instructional methods used by teachers in traditional and constructivist-learning environments share the general attributes of context, construction, and collaboration (Jonassen as cited in Maddux, Johnson, \& Willis, 2001) but differ in their centeredness. Traditional environments tend to be teacher-centered in design while constructivist environments tend to be student-centered. To get an idea of the instructional methods used in the learning environments under study see Table 2 later in this paper.

Contextual attributes include instructional methods that serve as mental bridges for learning. The purpose is to model the intention of the instruction for students, thereby allowing them to observe and reflect through the sharing of thoughts and ideas that provide for the consideration of alternate perspectives (Michael \& Modell, 2003). One contextual instructional method is simulation, descriptions of events or conditions that often allow the user to change variables to see the impact of that change (Maddux et al., 2001). Simulations include computer animations, computer games, exercises, and assorted learning media that simulate learning experiences for students. Contextual methods were evaluated in a few studies, mostly involving computer programming indicated mixed results. Two studies reported that creating animations helped students better understand concepts taught (Smith \& Escott, 2004; Stasko, 1997), while another reported no statistically significant improvement when animations were used as teaching tools (Naps, et al., 2002). In another study, computer game use was favorable due to feedback providing instant gratification (Natvig \& Line, 2004). Constructivist methods serve to build knowledge through worked examples such as writing, discussing, and reflection as a self-evaluation of progress toward conceptual understanding (Andrusyszyn \& Davie, 2001). Research studies evaluated that involved construction strategies of writing, discussing, and reflection revealed positive results (Bhagyavati, Kurkuvsky, \& Whitehead, 2005; Dugan \& Polanski, 2006; Syrjala, 1996) due to the methods that allowed the sharing of experiences, which led to growth through refection of learned content. Collaboration methods serve to develop negotiation skills by establishing and interacting with peer groups (Maddux et al., 2001). The research studies evaluated revealed that group work helps students build awareness of self and others, citing listening skills, social skills, time management, and organizational skills as the top most improved skills (Backhouse, 2005; Ong, 2000; Whittington, 2004) developed through collaborative instructional methods.

In summary, the studies discussed in the previous section indicated that the instructional methods used produced one or more of the following results via self-report: better understanding of concepts taught, increased motivation to learn, increased course participation, improved attitudinal disposition, and increased awareness of the self and how one learns. Although it is clear that students perceived these instructional methods as positive, it is not clear if the methods of instruction correlated with academic achievement. It is important to note that the results indicated in these studies may overestimate what students think they learned, as novel instructional approaches and self-report tools may be influencing factors. To triangulate this hunch, the investigators in two of the nine studies measured student perceptions against instructor observations; confirming stated 
results (Backhouse, 2005; Bhagyavati et al., 2005). Since positive findings were reported, it seems to be a given that undergraduates prefer to use active learning techniques in their college classrooms.

\section{College Student Learning Preferences}

The 1.7 million high school graduates currently entering higher education have learning preferences of trial-and-error, similar to the way they grew up playing games on a Nintendo system and the like, and favor tactile and kinesthetic learning activities (Davis, 1999; Snyder, 2003). They represent a learning culture surrounded by digital tools - computers, software, the Internet, videogames, digital music players, video cams, instant messaging, and cell phones - and where using them daily for home and school is the norm (Kaiser Family Foundation, 2009; Speak Up, 2009).

Although the paradigm shift to instructional methods that befit the learning preferences of today's undergraduates began many years ago (Barr \& Tagg, 1995; Cross, 2001), lecture is still the most widely used teaching method in undergraduate classrooms (Bok, 2005; "Faculty Survey of Student Engagement," 2009). This method of teaching is still widely used, even when it is reported that academic success and failure depends not on student characteristics or teaching effectiveness alone, but on the interactions between the students and the learning environments, and the match between presented materials and how students process them (Abrantes, Seabra, \& Lages, 2007; Drysdale, Ross, \& Schulz, 2001; Young, Klemz, \& Murphy, 2003). Further, student interest is realized by the interactions they have with their instructors, in an environment that provides an opportunity to ask questions, express ideas, and have open discussions in class. The key aspect to these interactions is instructor responsiveness (Abrantes et al., 2007). In a lecture-based classroom, student-teacher interactions are often limited. Use of classroom interaction parallels Chickering and Gamson's (1987) framework, which outlines seven engagement indicators predicted to influence the quality of undergraduate students' learning and their educational experiences. One of the principles most relevant to this study is the use of active learning techniques, which suggest that instructors use instructional methods that are effective, relevant, and satisfactory to motivate students to obtain better learning results.

\section{Learner Characteristics}

The literature reports four factors known to affect students' academic achievement in IT-related courses besides instructional methods. They are mathematical background, mathematical ability, cumulative grade point average, and learning style; these are referred to as learner characteristics. Discrete mathematics or Calculus constitutes a significant factor in academic achievement in computing courses (Pioro, 2006; Wilson \& Shrock, 2001). In the current study, mathematical background is defined as completing Calculus or Discrete courses.

Studies reporting the mathematical ability of students, defined by the final grade on a high school math exam, were the top variable predicting academic achievement (Bennedsen \& Caspersen, 2005). In the current study, mathematical ability was reported as math SAT score, a quantitative score received on the standardized mathematical SAT aptitude exam taken as a high school student, with a maximum possible total of 800 points. Cumulative grade point average (CGPA) is defined as the average grade earned by a student, determined by dividing the grade points earned by the number of credits attempted. It was the single largest factor in predicting the total points earned in a course that introduced fundamental technical aspects of personal computers (Kruck \& Lending, 2003) and correlates with academic achievement in an introductory computer end-user technology course (Chenoweth, 2005). 
Learning style refers to the ways in which thought is structured within an individual. Their behavioral consistency is a result of this structure (Goldstein \& Blackman, as cited in Moldafsky \& Kwon, 1994). Most learning style theorists place learning preferences in distinct dimensions or modes. To measure attributes, self-reported learning style instruments are most often used, such a Kolb's, which consists of four different styles: accommodating, assimilating, converging, and diverging.

There is a reported linkage between college level learners with dominance in the assimilating and converging learning styles and academic achievement in IT-type courses using various iterations of Kolb's (LSI) classification. Results indicated that undergraduate students with a penchant toward the abstract conceptualization mode (found in Kolb's assimilating and converging learning styles) performed better in the introductory computer science courses than students with other learning style preferences (Chamillard \& Karolick, 1999; Chamillard \& Sward, 2005; Goold \& Rimmer, 2000; Hudak \& Anderson, 1990; Thomas, Ratcliffe, Woodsbury, \& Jarman, 2002). However, we still do not know enough about the relationship among all the learner characteristics in terms of how they interact with learning environment to influence academic achievement and satisfaction in IT-related courses. This was an important consideration in the current study whose main premise was that all types of learners may learn IT concepts better and experience higher levels of satisfaction when taught in constructivist environments.

\section{Research Questions}

1. What is the relationship between learner characteristics (math background, math ability, grade point average, and Kolb's four learning styles: accommodating, assimilating, converging, and diverging) and IT fluency?

2. What is the relationship between learner characteristics and course satisfaction?

3. What is the relationship between learning environment and IT fluency, after controlling for any effects associated with learner characteristics?

4. What is the relationship between learning environment and course satisfaction, after controlling for any effects associated with learner characteristics?

5. How do learning environment and learner characteristics interact to explain IT fluency?

6. How do learning environment and learner characteristics interact to explain course satisfaction?

\section{Research Design}

This causal-comparative study explored the relationships between the independent variable of learning environment to the dependent variables of IT fluency and satisfaction of students in two non-randomized groups. In addition, further exploration determined whether any differences found between the two groups were explained by another difference that existed, specifically, the moderating variables of math background, math ability, cumulative grade point average, and/or learning styles. As is the case in causal-comparative research, the investigator did not attempt to control or manipulate any variables (Creswell, 2002). Instead, statistics were used to control for factors and to examine the combination of those factors that affected outcomes, specifically analysis of covariance.

\section{Participants}

Undergraduates $(\mathrm{n}=294)$ at a mid-size university in the New York metropolitan area who had completed an initial computer course, received an email invitation to participate. Institutional consent for conducting the study was obtained. 


\section{Modes of Inquiry}

Data describing students' experiences and scores were collected using four instruments: (i) Kolb Learning Styles Inventory, (ii) Evaluation of Teaching Effectiveness, (iii) Departmental Final Exam, and (iv) Learner Characteristics. Numerous learning style inventories are available and were considered for use in this study. The candidates were Kolb's Learning Style Inventory (Kolb \& Kolb, 2005), Canfield's Learning Style Inventory (1980), Dunn Learning Styles Model (Dunn, 1990), Myers-Briggs' Type Inventory (Myers \& McCaulley, 1985), and Felder-Soloman Index of Learning Styles (Felder \& Soloman, 1991). After evaluating the aforementioned inventories, the Kolb's Learning Style Inventory (KLSI 3.1) was chosen for applicability to research purpose and its recency and use on other studies.

Kolb is the most widely used learning style inventory measuring cognitive traits, which then categorizes learners as accommodators, assimilators, convergers, and divergers (Kolb, 1985). Kolb identified four types of learning modes and four learning styles, where learning style is the combination of two specific learning modes and is designed to help individuals identify the way they learn from experience. The instrument contains twelve items that asked respondents to rank-order the four sentence endings in a way that best described their learning style. One sentence ending in each item corresponded to one of the four learning modes - concrete experience, reflective observation, abstract conceptualization, or active experimentation. Each of these modes is combined with another to form one specific learning style. Assimilating combines the modes of abstract conceptualization and reflective observation; accommodating combines the modes of concrete experimentation and active experimentation; converging combines the modes of abstract conceptualization and active experimentation; and diverging combines the modes of concrete experimentation and reflective observation. The four scales of Kolb's Learning Style Inventory (KLSI 3.1) show good internal consistency reliability with Cronbach's alpha coefficients for the four scales ranging from .77 to .84 and test-retest reliability greater than 0.9 in all cases (Kolb \& Kolb, 2005; Stangor, 1998).

The second instrument, Evaluation of Teaching Effectiveness, measures course satisfaction as experienced by students in a given course (Serva \& Fuller, 1999). Eight constructs of the teaching dimension were included in this instrument: class organization, active learning, media use, grading fairness, workload, student perceived performance, instructor relationship with students, and instructor knowledge of the material (Appendix A). This particular instrument was selected for use because it included two new constructs, active learning and effective media use, which were important to the study. This instrument is a Likert-scale, consisting of a series of items that indicate the degree of agreement or disagreement with the measured issue, each with a set of responses that indicate respondent opinion (Stangor, 1998). The Evaluation of Teaching Effectiveness Scale contained 28 items, each a seven-point response continuum representing agreement, ranging from strongly disagree to strongly agree. The authors granted the researcher permission to use the instrument. The dimensions of the Evaluation of Teaching Effectiveness show fair internal consistency reliability using an Analysis of Covariance Structural method with coefficients ranging from 0.54 to 0.89 (Serva \& Fuller, 1999). Convergent validity of this instrument measuring the extent of agreement between two different measures of a theoretical construct was determined according to statistical factor loading guidelines (Stevens, 1986). In addition, this instrument satisfied the statistical test for discriminant validity, which tests the null hypothesis that two constructs measure the same theoretical concept.

The third instrument, a departmental final exam designed to measure IT fluency, was provided by Thomson Prometric, specifically, the Dantes Subject Standardized Test (2005), Introduction to Computing. Topics on the exam matched $80 \%$ of the course content. Three full-time faculty who taught the course, including the researcher, adapted the exam. The topics taught in the course, as well as what topics were assessed on this exam, are listed in Table 1. In the final version, the de- 
partmental exam consisted of 50 objective, single-best-answer, multiple-choice questions. This multiple choice assessment format was chosen based on the assertions that converging and assimilating learners have a performance advantage when this type of format is used (Kolb, 1985; Newland \& Woelfl, 1992). The idea was that if students other than those with converging and assimilating learning styles scored higher on the final exam than those with these preferences, then the final exam scores may have been the result of factors other than learning styles. The departmental exam was administered to all students enrolled in the course. Each participant earned a score after taking the final exam. This score was dependent variable, IT fluency.

The norming process for the Dantes Introduction to Computing test was completed by students from higher education institutions $(n=550)$ of various sizes ranging from large state universities to small private and community colleges. Scores ranged from 20 to 80; with a mean of 50; and a standard deviation of 10. The Kuder-Richardson 20 (KR-20) internal consistency reliability coefficient for this exam was 0.91 .

The fourth and final instrument used to collect data was the Learner Characteristics (Appendix B). These questions pertained to students' mathematical background, mathematical ability, and cumulative grade point average. Mathematical background was indicated with a 'yes' or a 'no' answer when asked whether the student had completed a calculus and/or discrete math course. Mathematical ability was indicated by the student as their SAT mathematical score. Last, students were asked to provide their cumulative grade point average (CGPA). Each of these was a moderating variable.

\section{Procedures}

The researcher invited 294 undergraduates who had completed a required fundamental computer course to participate in this study. The email message informed students of the voluntary nature of the study and their right to withdraw at any point. The email message asked students to authorize the release of their final exam score to the researcher. The email message contained the survey attachments. Students who opted to participate in the research study completed: (1) the Kolb Learning Style Inventory, (2) the Evaluation of Teaching Effectiveness Scale, and (3) Learner Characteristics. The surveys were then emailed back to the researcher. Follow-up via email took place after two weeks for each group. By the end of twelve weeks, 124 responses had been received. The respondents were compensated with a $\$ 10.00$ gift card redeemable at the campus bookstore and offered a chance to win an iPod MP3 digital music player ( $\$ 199$ value) upon conclusion of the data collection process.

\section{Data Analysis}

The independent variable, learning environment at two levels (traditional and constructivist), was a dichotomous categorical variable. Two of the moderating variables, learning styles (of which there were four different styles) and mathematical background (calculus and discrete math) were also dichotomous categorical variables. The other moderating variables of mathematical ability (SAT math score) and cumulative grade point average (CGPA) were continuous variables as were the two dependent variables, IT fluency and course satisfaction.

Data describing students' experiences and scores were collected using the four instruments. The Kolb Learning Styles Inventory had items that needed to be tallied and coded according to a key provided by The Hay Group, provider of the instrument. Learning styles were coded as (1) accommodating, (2) assimilating, (3) converging, and (4) diverging. Each participant received one of these codes based on their answers. The second instrument, Evaluation of Teaching Effectiveness Scale, had items that needed reverse coding. It was determined that the total score of the scale was 196 . Each survey was tallied by adding the scores on each of the 28 items together to 
get one composite score per survey. Composite score on this instrument was one of the dependent variables, course satisfaction. For the third instrument, Departmental Final Exam, scores were obtained from course instructors after receiving permission from participants. The exam score was the dependent variable, IT fluency. The last instrument, Learner Characteristics, had two items that needed recoding. Mathematical background indicating whether a student had a courses in calculus and/or discrete mathematics were coded (1) for yes and (0) for no.

Each of the statistical analyses was performed using predictive analytic software, SPSS for Windows (v15), with a minimum alpha of .05. An analysis of the ratio of cases to independent variables was performed, adhering to the suggested minimum requirement: $\mathrm{N}>=50+8 m$, (where $m$ is the number of IVs) (Tabachnick \& Fidell, 2007). This assumed a medium-size relationship between the IVs and the DVs, alpha $=.05$ and $\beta=.20$. Based on this assumption, a sample size of 122 was sought: $[122=50+8(9)]$, where nine was the number of IVs to include (1) learning environment, (2) moderating variables of math background, (1) SAT math score, (1) CGPA, and (4) learning styles. This was confirmed via an apriori power analysis for ANOVA using the software program G*POWER, where a sample size of 120 was recommended (Faul \& Erdfelder, 1992).

To assure the quality of the collected data, a data screening process was completed. This began with a frequency procedure establishing mean, standard deviation, and variance to explore and address any issues of missing data, outliers, normality of distribution, homogeneity of variance, and homogeneity of regression slopes using the SPSS Explore function. Due to the existence of asymmetric suspicious outliers, four cases were eliminated from the sample, improving the distribution significantly, thus reducing the sample to 120 cases; 53 students in the traditional and 67 students in the constructivist-learning environment. Q-Q plots revealed normal distributions for both of the dependent variables.

To confirm that students in the traditional learning environment and the constructivist learning environment were comparable, independent samples $t$-tests were conducted ( $p=.05$ level of confidence). These tests compared the two groups on potentially relevant variables of learning styles, cumulative grade point average, math background (discrete math and/or calculus), and mathematical ability (SAT math score). Data on these variables were collected from the Learner Characteristics and the Kolb Learning Styles Inventory. There were no significant differences between the students in the two learning environments with respect to learning styles, cumulative grade point average, discrete math, and SAT math score. There was a significant difference between the two learning environments regarding the variable calculus, where more students in the traditional environment $(M=.51 ; S D=.505)$ had a background in calculus than students in the constructivist learning environment $(M=.27 ; S D=.447)(p=.007)$.

To test for the existence of mean differences in IT fluency based on instructor, a one-way analysis of variance (ANOVA) technique was administered. Results indicated no statistically significant difference existed among the four instructors in relationship to IT fluency, $F(3,116)=1.075, p=$. 363. To test the time of day the course met for mean differences in IT fluency, another one-way analysis of variance (ANOVA) test was conducted. The results indicated that no statistically significant difference existed between the time of day the section met and IT fluency, $F(1,118)=$ $.066, p=.797$.

To determine if a relationship existed between the two dependent variables, IT fluency and course satisfaction, a scatter plot was created. The visual impression confirmed that the dependent variables, IT fluency and course satisfaction, were independent of one another; meaning a score on one variable did not predict the score on the other variable. Therefore, any further analyses combining these two variables were not warranted. This was important to determine prior to running the data analysis because if the two dependent variables were related, a different statistical analy- 
sis would have been performed; specifically, a multivariate analysis of covariance (MANCOVA) technique.

Research data needed to satisfy certain statistical assumptions before the analysis of covariance (ANCOVA) could be tested were confirmed. A preliminary ANCOVA was conducted to test for homogeneity of variance and homogeneity of regression slopes for both of the dependent variables to determine if significant interaction(s) between the covariates and the factors was present. Levene's Test for equal variances indicated that variances between groups were fairly equivalent for the dependent variable, IT fluency, $F(1,118)=.098, p=.755$. Levene's Test for equal variances indicated that variances between groups were fairly equivalent for the dependent variable, course satisfaction, $F(1,119)=2.449, p=.120$. The test of the homogeneity of the regression slopes indicated no significant interactions between the factors and the covariates for effect on IT fluency or for effect on course satisfaction.

To determine whether a relationship existed between the independent and dependent variables in this study, an analysis of covariance (ANCOVA) statistical technique was conducted. Another ANCOVA was then further tested to determine if any differences found between the groups was explained by another variable(s); specifically, the moderating variables of math background, math ability, cumulative grade point average, and/or learning styles. This technique (ANCOVA) was chosen because it merged numerous statistical tests into one: analysis of variance, covariance, and linear regression. Since known predictors of IT fluency were included in the data set, the ANCOVA tested whether certain factors had an effect after removing the variance for which the quantitative predictors (covariates) accounted. Also, the ANCOVA technique allowed for the creation and analysis of any interactions between pairings of independent and moderating variables (Mertler \& Vannatta, 2002). Interactions were created as a cross-product of the independent variable (learning environment) and the predictor variables. This determined the specific amount of variance that any of the moderating variables accounted for, beyond what had been previously explained.

\section{Findings}

Research Question One: "What was the relationship between learner characteristics (math background, math ability, cumulative grade point average, and Kolb's four learning styles: accommodating, assimilating, converging, and diverging) and IT fluency?" To answer this research question, an analysis of covariance (ANCOVA) technique was performed to fit a full model that included all learner characteristics to determine if a relationship existed between any of these variables and the dependent variable, IT fluency. The statistical significance of all eight variables was tested by the $F$ ratio. The ANCOVA result indicated a significant main effect for cumulative grade point average, $F(1,112)=23.912, p<.000$, partial eta squared .176 and a significant main effect for SAT math, $F(1,112)=5.908, p=.017$, partial eta squared .050 . CGPA was higher in the constructivist group $(M=3.40 ; S D=.473)$ than the traditional $(M=3.27 ; S D=.522)$ and SAT Math was higher in the constructivist group $(M=541.19 ; S D=80.74)$ than the traditional $(M=530$; $S D=64.98)$.

However, the results of the full model were contrary to the learning styles literature, where assimilating learning style is a well-founded predictor of academic achievement in IT-related courses. To take a closer look at this particular variable, a further reduced model was tested by the $F$ ratio. The ANCOVA result indicated a significant main effect for cumulative grade point average, $F(1,116)=22.6, p<.000$, partial eta squared .163; a significant main effect for SAT math, $F(1,116)=9.601, p=.002$ partial eta squared .076; and a significant main effect for assimilating learning style, $F(1,116)=3.949, p=.049$, partial eta squared .033 . In the reduced model, learning style was found to have a relationship with IT fluency, where students with assimilating learning style studying in the traditional environment scored higher on the final exam 
than other students in the traditional environment. Yet, the final exam scores for students in the traditional environment $(M=.21 ; S D=.409)$ were not statistically significant as compared to the constructivist group environment $(M=.18 ; S D=.386)$. It is important to note that the type of assessment used to measure IT fluency was a single-best-answer, multiple-choice exam, in which converging and assimilating learners have a performance advantage (Kolb, 1985; Newland \& Woelfl, 1992). According to the research literature, using such a format should have resulted in the traditional group performing statistically higher compared to students in the constructivist group, which did not happen.

Research Question Two: "What was the relationship between learner characteristics (math background, math ability, cumulative grade point average, and four learning styles) and course satisfaction?" To answer this research question, an analysis of covariance (ANCOVA) technique was performed to fit a full model including all eight moderating variables associated with learner characteristics to determine if a relationship existed between these variables and the dependent variable, course satisfaction. The statistical significance of the eight variables was tested by the $F$ ratio. ANCOVA result for the full model indicated a significant main effect for cumulative grade point average, $F(1,112)=5.239, p=.024$, partial eta squared .045 and accommodating learning style, $F(1,112)=4.939, p=.028$, partial eta squared .042 . CGPA was higher in the constructivist group $(M=3.40 ; S D=.473)$ than the traditional $(M=3.27 ; S D=.522)$ and accommodating learning style slightly higher in the traditional group $(M=.38 ; S D=.489)$ than the constructivist $(M=.36$; $S D=.483$ ). The relationship between cumulative grade point average and course satisfaction is supported in the literature and confirmed in this study, where statistically significant course satisfaction was found in the constructivist environment $(M=170.66 ; S D=11.27)$ compared to the traditional environment $(M=164.61 ; S D=13.80), p=.009$.

Research Question Three: "What was the relationship between learning environment and IT fluency, after controlling for any effects associated with learner characteristics?" To answer this research question, an ANCOVA technique was performed, adding the independent variable, learning environment, to the reduced model to determine if a relationship existed between the independent variable (learning environment) and the dependent variable (IT fluency) while controlling for known main effects (cumulative grade point average, SAT math, and assimilating learning style). ANCOVA result indicated no statistically significant relationship for any factors, as follows: learning environment and cumulative grade point average $F(1,112)=2.505, p=.116$, partial eta squared .022; learning environment and SAT Math $\mathrm{F}(1,112)=.869, \mathrm{p}=.353$, partial eta squared .008; also, learning environment and assimilating learning style $\mathrm{F}(1,112)=.112, \mathrm{p}=$ .738 partial eta squared .001 . Although IT fluency did not vary significantly with learning environment after controlling for the known effects, it may have been the learner characteristic factors of SAT math, assimilating learning style, and specifically, cumulative grade point average, outweighed any additional effects.

Research Question Four: "What was the relationship between learning environment and course satisfaction, after controlling for any effects associated with learner characteristics?" To answer this research question, an ANCOVA technique was performed, adding the independent variable, learning environment, to the reduced model to determine if a relationship existed between the independent variable (learning environment) and the dependent variable (course satisfaction) while controlling for known main effects (cumulative grade point average and accommodating learning style). ANCOVA result indicated no statistically significant relationship for any factors, as follows: course satisfaction and cumulative grade point average $\mathrm{F}(1,114)=.023, \mathrm{p}=.879$ partial eta squared .000; also, course satisfaction and accommodating learning style $F(1,114)=.034$, $\mathrm{p}=.853$ partial eta squared .000 . Although course satisfaction did not vary significantly with learning environment after controlling for the known effects, it may have been the learner charac- 
teristic factors of accommodating learning style, and specifically, cumulative grade point average, outweighed any additional effects.

Research Question Five: "How did learning environment and learner characteristics interact to explain IT fluency?" To answer this research question, an ANCOVA technique was performed, adding the interaction variables (each of the significant learner characteristics by learning environment) to the existing model to determine if a relationship occurred between the interaction variables and the dependent variable, IT fluency. The statistical significance of the independent variable was tested by the $F$ ratio. ANCOVA result indicated no statistically significant interaction effect, $\mathrm{F}(1,112)=.159, \mathrm{p}=.691$, partial eta squared .001 .

Research Question Six: "How did learning environment and learner characteristics interact to explain course satisfaction?" To answer this research question, an ANCOVA technique was performed, adding the interaction variables (each of the significant learner characteristics by learning environment) to the existing model to determine if a relationship occurred between the interaction variables and the dependent variable, course satisfaction. The statistical significance of the independent variable was tested by the $F$ ratio. ANCOVA result indicated no statistically significant interaction effect, $\mathrm{F}(1,114)=.032, \mathrm{p}=.858$, partial eta squared .000 .

To determine the type of activities that were designed for each learning environment, an analysis of instructors' syllabi was completed. Attention was given to the type and frequency with which instructor practice matched the general attributes of instructional strategies: contextual, construction, and collaboration. Table 2 lists the types of activities used in the instructors' practice, created to determine if differences existed in the teaching materials among the two study groups: traditional and constructivist.

Differences were found in each of the three categories. In the contextual category, instructors who taught in the constructivist environment provided more opportunities for learning course content through student presentations, digital learning game play, and peer feedback than in the traditional environment. The traditional environment had a greater frequency of quizzes, lectures, and use of the direct instruction method of teaching. In the construction category, students had the opportunity to develop their online portfolio, write reflectively, and engage in both class discussions and media resources as a way to build their knowledge in the constructivist environment while the traditional environment asked students to perform more structured activities such as writing a research paper and responding to a provided ethical case study. Lastly, the number and type of collaboration activities varied by learning environment. The constructivist environment provided greater amounts of group work and problem-solving activities than the traditional environment, although this environment did provide the opportunity to work in pairs.

To determine if the noted differences were statistically significant, an Independent Sample $t$-test compared participants' responses on the Evaluation of Teaching Effectiveness scale, grouped by learning environment. The eight constructs of the teaching dimension included in this instrument were class organization, active learning, media use, grading fairness, workload, student perceived performance, instructor relationship with students, and instructor knowledge of the material. Differences were found on items within the dimensions of active learning, class organization, media use, workload, and student perceived performance.

Statistically significant differences were found on items associated with the active learning dimension in terms of instructional methods used. On the item "instructor promoted discussion," the means differed significantly at the $p<.001$ level (2-tailed), where students in the constructivist environment scored higher $(M=6.67 ; S D=.561)$ than the traditional group ( $M=6.06$; $S D=1.099$ ). The next finding was item "instructor raised challenging questions," had means that differed significantly at the $p<.001$ level, (2-tailed), where instructors in the constructivist envi- 
ronment scored higher $(M=6.13 ; S D=.796)$ than instructors in the traditional group $(M=5.08$; $S D=1.385)$.

Table 2.Course Syllabi - Analysis of Strategies Used in Two Learning Environments

\begin{tabular}{|c|c|c|c|c|}
\hline \multirow[b]{2}{*}{ Instructor Number } & \multicolumn{2}{|c|}{$\begin{array}{l}\text { Constructivist } \\
\text { Environment }\end{array}$} & \multicolumn{2}{|c|}{$\begin{array}{c}\text { Traditional } \\
\text { Environment }\end{array}$} \\
\hline & 1 & 2 & 3 & 4 \\
\hline \multicolumn{5}{|l|}{ Contextual Strategies } \\
\hline $\begin{array}{l}\text { Virtual Simulations } \\
\text { (Games, Exercises, } \\
\text { Media, Computer Use) }\end{array}$ & $\mathrm{X}$ & $\mathrm{X}$ & & \\
\hline Lecture $>20$ min & & & $\mathrm{X}$ & $\mathrm{X}$ \\
\hline \multicolumn{5}{|c|}{ Construction Strategies } \\
\hline Peer Feedback & $\mathrm{X}$ & $\bar{X}$ & & \\
\hline $\begin{array}{l}\text { Online Portfolio } \\
\text { Development }\end{array}$ & $\mathrm{X}$ & $\bar{X}$ & & \\
\hline Research Paper & & & $\mathrm{X}$ & $\mathrm{X}$ \\
\hline Class Discussions & $\mathrm{X}$ & $\bar{X}$ & & \\
\hline Reflective Journals & $\mathrm{X}$ & $\mathrm{X}$ & & \\
\hline Case Study & & & $\mathrm{X}$ & $\mathrm{X}$ \\
\hline \multicolumn{5}{|c|}{ Collaboration Strategies } \\
\hline Group Work & $\mathrm{X}$ & $\mathrm{X}$ & & \\
\hline \multicolumn{5}{|l|}{ Assessment Strategies } \\
\hline Student Presentations & $\mathrm{X}$ & $\mathrm{X}$ & & \\
\hline Quizzes & & & $\mathrm{X}(5)$ & $\mathrm{X}(8)$ \\
\hline Final Exam & $\mathrm{X}$ & $\mathrm{X}$ & $\mathrm{X}$ & $\mathrm{X}$ \\
\hline
\end{tabular}

Statistically significant differences were found on an item associated with the class organization dimension. Students in the constructivist learning environment $(M=6.37 ; S D=.648)$ reported a greater understanding of the course objectives than students in the traditional environment $(M=6.02 ; S D=.888)$, where the means differed on the item "course objectives were clearly defined," statistically significant at $p=.013$ (2-tailed). On the media use dimension, the Independent Samples $t$-test indicated that the means on the item "instructor used media effectively," differed significantly at the $p=.040$ (2-tailed), where instructors in the constructivist group $(M=6.78 ; S D=.487)$ scored higher than instructors in the traditional group $(M=6.51 ; S D=.823)$. Significant differences were also found on the item "media used helped make the course interesting" where the mean in the constructivist group $(M=6.27 ; S D=.863)$ was statistically significantly higher than the mean in the traditional group $(M=5.64 ; S D=1.210) p=.002$ (2-tailed).

On the student perceived performance dimension, statistically significant mean differences ( $p=.031$; 2-tailed) were found on the item "I learned a lot from the course," where the mean in the 
constructivist learning environment $(M=6.09 ; S D=.917)$ was higher than the mean in the traditional group $(M=5.62 ; S D=1.319)$. Interestingly, although the perceived amount of learning and clarity of expectations were significant in the constructivist group, the workload, another dimension, differed in the two environments. Items "course covered too much material" $(p=.008,2-$ tailed) and "assignments were too difficult" ( $p=.034,2$-tailed) were statistically higher in the constructivist environment. The item "course covered too much material" was higher $(M=3.85$; $S D=1.672)$ than the traditional group $(M=3.02 ; S D=1.704)$ and item "assignments were too difficult" was higher in the constructivist group $(M=2.07 ; S D=1.172)$ compared to the traditional group $(M=1.68 ; S D=.850)$.

These findings exposed learning differences in the two environments and indicated how these differences, tied to instructional methods and materials used in college classrooms, may have affected IT fluency. These findings are similar to prior research studies that suggested students learn more in environments where instructional methods are congruent with their preferences such as using active learning techniques.

\section{Conclusions}

The major conclusion that can be drawn based on the findings of this study are constructivistlearning environments where active learning strategies are used negate the influence of preferred learning style. In addition, students are challenged by rigorous academic curricula and favor certain instructional methods and strategies, deeming them as significant to their learning.

Finding One: There was no statistical difference in IT fluency based on the environment [traditional or constructivist] in which students studied. However, in the constructivist group, no relationship was found between an individual's preferred learning style and IT fluency, meaning that active learning strategies negate the influence of preferred learning style. This is in contrast to the traditional learning environment, where students who had assimilating leaning style preferences performed better than other students who studied in the same environment. This finding indicates that active learning strategies found in constructivist environments meet the learning preferences of all students.

Finding Two: Specific instructional methods and processes were perceived as more appealing to students studying in the constructivist environment. Therefore, it is suggested that the constructivist methods used were motivating, engaging, and fit the ways in which these students wanted to learn and interact with their instructor. Examples of the active learning methods used were student presentations, simulations and game play, peer feedback, development of online portfolios, use of media resources, reflective writing exercises, engagement in class discussions, and group work. The specific instructional strategies used by the instructors in the constructivist environment included (i) raising challenging questions for students; (ii) promoting discussion; (iii) using varied media effectively; and (iv) providing challenging assignments.

There were some weaknesses in the research methodology used in this study. First, there was a decisive gap between the time participants completed the course and the time when asked to answer the survey questions, which is in line with the reflection literature. However, the amount of time given to each participant was not even. Some participants had two years, while others had six months to think about what they learned in the course. The correct amount or effects of an uneven amount of time provided to people to engage in reflective activities is, at present, not found in the reflection literature. Second, this was a sample of convenience in a university setting and students were required to enroll in the computer course. The generalizability of this study is limited insofar as the learning style inventory, course satisfaction survey, and learner characteristics are all self-report measures. Moreover, participants were enrolled at a mid-sized university in 
the New York metropolitan area that supports learning through information technology initiatives.

\section{Recommendations}

The following recommendations are geared to two audiences: (i) instructors in higher education technology programs interested in designing instruction in conjunction with constructivist learning environments, and (ii) researchers. It is recommended that college instructors in business/technology programs consider using constructivist environments as they produce both high exam scores and high levels of course satisfaction and negate any learning style biases.

Deployment of constructivist learning environments based on active learning strategies are advised in an effort for students to become IT fluent and, thus, provide a foundation for adaptability within the labor market. An IT fluent student would have the skills, concepts, and intellectual capabilities related to information in terms of its representation, structure, organization, processing, transmission, distribution, and the technologies involved in the interactive execution of those activities--computers, networks, and software. IT fluency learned in a constructivist environment may increase the number of students attracted to math and science fields. Active methods of instruction engage students to the point where they are often unaware of how much they are learning at the time due to deep immersion in learning tasks. Yet, once students are asked to reflect, realization of the depth and breadth of their learning occurs.

Since reflective thinking does not necessarily occur as part of natural undergraduate development, it is recommended that instructors model the reflective process and provide assignments that elicit self-evaluative responses. Within the constructivist environment, it is advised that the following active learning methods of instruction be used: student presentations, simulations and game play, peer feedback, development of online portfolios, use of media resources, reflective writing exercises, engagement in class discussions, and group work. The specific instructional strategies suggested for use in the constructivist environment include (i) raising challenging questions for students, (ii) promoting discussion, (iii) using varied media effectively, and (iv) providing challenging assignments deemed relevant for learning.

An example of a learning activity designed for a constructivist environment would involve learning how digital data is represented and processed. First, students would watch a simulation teaching that computers only understand machine language and, yet, input is done using "human language" via input devices like a computer keyboard. Students would watch and learn how letters on a computer keyboard are translated into data bits (binary code), which travel along a data bus on a computer motherboard. Then, actual laptop motherboards would be provided to students working in small groups. Students would be provided with a challenging task, such as determine the IPOS cycle (Input-Processing-Output-Storage) by identifying the data path from input device to processor to output device to storage device.

Further, use of the Kolb Learning Styles Inventory is encouraged as it provides a starting point for curricular design. Results provide instructors with a window into their students' individual and aggregate learning preferences and its use conveys a message of caring, creating the first of many student-teacher interactions advised for use in constructivist environments.

A pre/post design is recommended for future research measuring students' pre-course knowledge of IT concepts to determine if differences in IT fluency and course satisfaction at course-end are related to learning environment. Also, a qualitative study is advised; perhaps a case study following participants throughout a semester to gauge their level of conceptual IT knowledge. This may provide insight as to how they solve real-life IT problems and how learning style and learning environment are related to contextual problem-solving. In addition, other conceptual frameworks might provide an idea as to how motivated today's students are to learn about IT concepts at the 
college level. The literature points to students as high technology users with low conceptual knowledge. As such, students may not be aware of how little they know about IT and when faced with the unfamiliar, they may lack motivation to learn. As a psychological construct, computer self-efficacy is believed to play a critical role in self-motivation, especially when a certain level of motivation is necessary to initiate coping with unfamiliar tasks. Therefore, it is recommended that students' computer self-efficacy as a measure of motivation be determined pre-treatment to see if this variable affects IT fluency and/or course satisfaction.

\section{References}

Abrantes, J., Seabra, C, \& Lages, L. (2007). Pedagogical affect, student interest, and learning performance. Journal of Business Research, 60(9), 960-964.

Andrusyszyn, M., \& Davie, L. (2001). Facilitating reflection through interactive journal writing in an online graduate course: A qualitative study. Journal of Distance Education, http://cade.athabascau.ca/vol12.1/andrusyszyndavie.html

Backhouse, J. (2005). Learning individual group skills for software analysis and design in Africa. Association of Computing Machinery. Proceedings of the SIGITE, Newark, New Jersey, 107-112.

Barr, R., \& Tagg, J. (1995). From teaching to learning - A new paradigm for undergraduate education. Change, 27(6), 12-25.

Bartholomew, K. (2004). Computer literacy: Is the emperor still exposed after all these years? Journal of Computing Sciences in Colleges, 20 (1), 323-331.

Bennedsen, J., \& Caspersen, M. (2005). An investigation of potential success factors for an introductory model-driven programming course. Association of Computing Machinery, Proceedings of the 2005 International Workshop on Computing Education Research, ICER, 155-163.

Bhagyavati, Kurkovsky, S., \& Whitehead, C. (2005). Using asynchronous discussions to enhance student participation in CS courses. Association of Computing Machinery, Technical Symposium on Computer Science Education, Proceedings of the 36th SIGCSE Technical Symposium on Computer Science Education, 111-115.

Blymier, B., Rockman, I., \& Williamson, D. (2005). Assessing students information and communication technology (ICT) skills: A new approach for higher education. (ID: WRC0547) Presented at Western Regional Conference, April 26-28, 2005 San Francisco, CA.

Bok, D. (2005, December 18). Are colleges failing? Higher ed needs new lesson plans. The Boston Globe online. Retrieved from http://www.boston.com/news/globe/editorial_opinion/oped/articles/2005/12/18/are colleges_failing/?p $\underline{\text { age }=1}$

Borrenson-Caruso, J., \& Salaway, G. (2007, September). EduCause study of undergraduate students and information technology (ECAR). Retrieved from http://www.educause.edu/ers0706

Canfield, A. (1980). Learning styles inventory manual. Ann Arbor, MI: Humanics Media.

Cavanagh, S. (2007, December 4). U.S. students fall short in math and science. Education Week online. http://www.edweek.org/ew/articles/2007/12/04/14pisa_web.h27.html?tmp=1842637310

Chamillard, A., \& Karolick, D. (1999). Using learning style data in an introductory computer science course. Association of Computing Machinery. Proceedings of the Thirtieth SIGCSE Technical Symposium on Computer Science Education, 31(1), 291-295.

Chamillard, A., \& Sward, R. (2005). Exploring student learning: Learning styles across the curriculum. Association of Computing Machinery. Proceedings of the 10th annual SIGCSE Conference on Innovation and Technology in Computer Science Education, ITiCSE, 241-245. 
Chen, C., \& Ray, C. (2004). The systematic approach in teaching database applications: Is there transfer when solving realistic business problems? Information Technology, Learning, and Performance Journal. 22(1), 9-21.

Chenoweth, J. (2005). Analyzing traditional factors for success in an introductory end-user technologies course. Information Technology, Learning, and Performance Journal, 22(3), 21-29.

Chickering, A., \& Gamson, Z. (1987). Seven principles for good practice in undergraduate education. AAHE Bulletin, 39(7), 3-7.

Colbeck, C., Cabrera, A., \& Terenzini, P. (2001). Learning professional confidence: Linking teaching practices, students' self-perception, and gender. The Review of Higher Education, 24(2), 173-191.

Computer Science and Telecommunications Board. (1999). Being fluent with information technology. Washington, DC: National Academies Press.

Creswell, J. (2002). Educational research. Upper Saddle River: Merrill Prentice Hall.

Cross, K. P. (1986). A proposal to improve teaching, or what 'taking teaching seriously' should mean. American Association for Higher Education Bulletin, 39(1), 9-14.

Cross, K. P. (2001). Leading edge efforts to improve teaching and learning. Change, July/August, 31-37.

Dantes Subject Standardized Test. (2005). Thomson Prometric. Retrieved from http://www.getcollegecredit.com/index.html\#

Davis, P. (1999). How undergraduates learn computer skills: Results of a survey and focus group. THE Journal, 26(9), 68-72.

Demetriadis, S., Triantfillou, E., \& Pombortsis, A. (2003). A phenomenographic study of students' attitudes toward the use of multiple media for learning. Association of Computing Machinery. Proceedings of the 8th Annual Conference on Innovation and Technology in Computer Science Education, 35(3), 183187.

Drysdale, M., Ross, J., \& Schulz, R. (2001) Cognitive learning styles and academic performance in 19 first year university courses: successful students versus students at risk. Journal of Education for Students Placed at Risk, 6(3), 271-289.

Dugan, R., \& Polanski, V. (2006). Writing for computer science: A taxonomy of writing tasks and general advice. Journal of Computing Sciences in Colleges, 21(6), 191-203.

Dunn, R. (1990). Understanding the Dunn and Dunn learning styles model and the need for individual diagnosis and prescription. Journal of Reading, Writing, and Learning Disabilities International, 6(3), 223-47.

Faculty survey of student engagement. (2009). Indiana University.

Faul, F., \& Erdfelder, E. (1992). G*POWER: Apriori, post-hoc, and compromise power analyses for MSDOS [Computer Program]. Bonn, FRG: Bonn University, Dept. of Psychology.

Felder, R. M., \& Soloman, B. A. (1991). Index of learning styles. Retrieved from http://www.ncsu.edu/felder-public/ILSpage.html

Forcier, R., \& Descy, D. (2002). The computer as an educational tool: Productivity and problem-solving. Upper Saddle River: Merrill Prentice Hall.

Fox, S., Anderson, J., \& Rainie, L. (2005). The future of the internet survey. Pew Internet and American Life Project. Retreived from http://www.pewinternet.org/pdfs/PIP_Future_of_Internet.pdf

Friedman, T. (2005). The world is flat. New York: Farrar, Straus and Giroux.

Gilpin, R. (2001). Global political economy: Understanding the international economic order. Princeton: Princeton University Press. 
Gonzales, G. (2006). A systematic approach to active and cooperative learning in CS1 and its effects on CS2. Association of Computing Machinery, Proceedings of the 37th SIGCSE Technical Symposium on Computer Science Education, 133-137.

Goold, A., \& Rimmer, R. (2000). Factors affecting performance in first-year computing. Association of Computing Machinery. SIGCSE Bulletin, 32(2), 39-43.

Hardy, C., Heeler, P., \& Brooks, D. (2006). Are high school graduates technologically ready for postsecondary education? Journal of Computing Sciences in Colleges, 21(4), 52-60.

Hoffman, M., \& Vance, D. (2004). Computer literacy: What students know and from whom they learned it. Association of Computing Machinery. Proceedings from 36th SIGCSE Technical Symposium on Computer Science Education, 37(1), 356-360.

Hudak, M., \& Anderson, D. (1990). Formal operations and learning style predict success in statistics and computer science courses. Teaching of Psychology, 17(4), 231-234.

Kaiser Family Foundation. (2009). Generation M2: Media in the Lives of 8- to 18-Year Olds. Retrieved from http://slides.kff.org/chart.aspx?ch=1351

Kaminski, K., Switzer, J., \& Gloeckner, G. (2009). Workforce readiness: A study of university students' fluency with information technology. Computers \& Education, 53, 228-233.

Kauchak, D., \& Eggen, P. (2003). Learning and teaching: Research-based methods. Boston: Allyn and Bacon.

Kesten, C., \& Lambrecht, J. (2010). Future direction for business education: A Delphi study. Delta Pi Epsilon Journal, 52(2), 57-76.

Klein, D., Cavanagh, R., Kay, K., \& Meisinger, S. (2006). Are they ready to work? Employers' perspectives on the basic knowledge and applied skills of new entrants into the 21st century US workforce. Retrieved from http://www.21stcenturyskills.org/documents/FINAL_REPORT_PDF09-29-06.pdf

Kolb, D. (1985). Experiential learning: Experience as the sources of learning and development. Upper Saddle River: Prentice Hall.

Kolb, A. \& Kolb, D. (2005). The Kolb learning style inventory - Version 3.12005 technical specifications. Retrieved from http://www.hayresourcesdirect.haygroup.com/\%20Learning_SelfDevelopment/Assessments_surveys/\%20Learning_Style_Inventory/lsipercent20techpercent20manual.pdf

Kruck, S., \& Lending, D. (2003). Predicting academic performance in an introductory college-level IS course. Information Technology, Learning, and Performance Journal. 21(2), 9-15.

Lui, A., Kwan, R., Poon, M., \& Cheung, Y. (2004). Saving weak programming students: Applying constructivism in a first programming course. Association of Computing Machinery SIGCSE Bulletin, $36(2), 72-76$.

Maddux, C., Johnson, D., \& Willis, J. (2001). Educational computing: Learning with tomorrow's technologies. Boston: Allyn \& Bacon.

Mertler, C., \& Vanatta, R. (2002). Advanced and multivariate statistical methods. Los Angeles: Pyrczak Publishing.

Michael, J., \& Modell, H. (2003). Active learning in secondary and college science classrooms. Mahwah, NJ: Lawrence Erlbaum Publishers.

Microsoft. (2005). Microsoft Windows history: Windows desktop timeline. Retrieved from http://www.microsoft.com/windows/WinHistoryProGraphic.mspx

Moldafsky, N., \& Kwon, I. (1994). Attributes affecting computer-aided decision making in a literature survey. Computers in Human Behavior, 10(3), 299-323.

Moncarz, R. (2002). Training for techies: Career preparation in information technology. Occupational Outlook Quarterly, Fall 2002, 38-45. Available from www.bls.gov/opub/ooq/2002/fall/art04.pdf 
Montgomery, K. (2007). Generation digital. Cambridge: The MIT Press.

Myers, I., \& McCaulley, M. (1985). Manual: A guide to the development and use of the Myers-Briggs type indicator (2nd ed.). Palo Alto, CA: Consulting Psychologists Press.

Naps, T., Rößling, G., Almstrum, V., Dann, W., Fleischer, R., Hundhausen, C., Korhonen, A., Malmi, L., McNally, M., Rodger, S., \& Velázquez-Iturbide, J. (2002). ITiCSE working group report: Exploring the role of visualization and engagement in computer science education. Association of Computing Machinery. SIGCSE Bulletin, 35(2), 131-152.

National Commission on Excellence in Education. (1983). A nation at risk: An imperative for educational reform. Retrieved from http://www.ed.gov/pubs/NatAtRisk/index.html

National Research Council. (1999). Being fluent with information technology. Computer Science and Telecommunications Board (CSTB) Washington, DC: National Academies Press.

Natvig, L., \& Line, S. (2004). Age of computers: Game-based teaching of computer fundamentals. Annual Joint Conference Integrating Technology into Computer Science Education, Association of Computing Machinery, Proceedings of the 9th annual SIGCSE Conference on Innovation and Technology in Computer Science Education, 107-111.

Newland, J., \& Woelfl, N. (1992). Learning style inventory and academic performance of students in general pathology. Bulletin of Pathology Education, 17, 77-81.

North Central Regional Educational Laboratory. (1995). Creating high-achieving learning environments. Retrieved from http://www.ncrel.org/sdrs/areas/issues/educatrs/leadrshp/le400.htm

Ong, R. (2000). The role of reflection in student learning: A study of its effectiveness in complementing problem-based learning environments. Retrieved from http://discovery.rp.edu.sg/home/ced/research/papers/role_of_reflection_in_student_learning.pdf

Pioro, B. (2006). Introductory computer programming: Gender, major, discrete mathematics, and calculus. Journal of Computing Sciences in Colleges, 21(5), 123-129.

Ravitz, J., Becker, H. \& Wong, Y. (2000, July). Constructivist-compatible beliefs and practices among U. $S$. teachers. Center for Research on Information Technology and Organizations. Retrieved from http://www.crito.uci.edu/TLC/FINDINGS/REPORT4/

Serva, M., \& Fuller, M. (1999). The role of media use and active learning in higher education: The development of an instrument to determine the dimensions of teaching. Proceeding of the 20th International Conference on Information Systems, Atlanta, GA: Association for Information Systems, 386-399.

Smaldino, S., Russell, J., Heinich, R., \& Molenda, M. (2005). Instructional technology and media for learning. Upper Saddle River: Prentice Hall.

Smith, G., \& Escott, E. (2004). Using animations to support teaching of general computing concepts. Association of Computing Machinery, Proceedings of the Sixth Australian Computing Education Conference 2004, Dunedin, New Zealand, 270-275.

Snyder, L. (2003). Fluency with information technology: Skills, concepts and capabilities. Boston: Addison Wesley.

SpeakUp. (2009). Creating our future: Students speak up about their vision for $21^{\text {st }}$ century learning. National Findings on Speak Up 2009. Retrieved from http://www.tomorrow.org/speakup/pdfs/SU09NationalFindingsStudents\&Parents.pdf

Stasko, J. (1997). Using student-built algorithm animations as learning aids. Association of Computing Machinery. Proceedings of the SIGCSE'97, 25-29.

Stangor, C. (1998). Research methods for the behavioral sciences. Boston: Houghton Mifflin.

Stevens, J. (1986). Applied multivariate statistics for the social sciences, Hillsdale, NJ: Lawrence Erlbaum Associates. 
Syrjala, L. (1996). The teacher as a researcher. In E. Hujala (Ed.) Childhood education: International perspectives. Finland: Association for Childhood Education International, Oulu University. ED 403069.

Tabachnick, B., \& Fidell, L. (2007). Using multivariate statistics (5th ed.). Boston: Allyn and Bacon.

Terrell, N. (2007). STEM occupations: High tech jobs for a high-tech economy. Occupational Outlook Quarterly. Spring 2007, 26-33, Available from http://www.bls.gov/opub/ooq/2007/spring/art04.pdf

Thomas, L., Ratcliffe, M., Woodsbury, J., \& Jarman, E. (2002). Learning styles and performance in the introductory programming sequence. Association of Computing Machinery, Proceedings of the 33rd SIGCSE Technical Symposium on Computer Science Education, 33 - 37

U. S. Department of Labor. (1999). Futurework: Trends and challenges for work in the $21^{\text {st }}$ century. A report of the U. S. Department of Labor, U. S. Government Respository. Retrieved from http://dol.gov/dol/asp/public/futurework

Whittington, K. (2004). Infusing active learning into introductory programming courses. Journal of Computing Sciences in Colleges, 19(5), 249-259.

Wilkerson, K. (2006). Students' computer literacy: Perception versus reality. Delta Pi Epsilon Journal, 48(2), 108-120.

Wilson, B. \& Shrock, S. (2001). Contributing to success in an introductory computer science course: A study of twelve factors. Association of Computing Machinery, SIGCSE Bulletin, Proceedings of the thirty-second SIGCSE Technical Symposium on Computer Science Education, 33(1), 184-188.

Wulf, T. (2005). Constructivist approaches for teaching computer programming. Association of Computing Machinery. Proceedings of the SIGITE, Newark, NJ, 245-248.

Young, M., Klemz, B., \& Murphy, J. (2003). Enhancing learning outcomes: The effects of instructional technology, learning styles, instructional methods, and student behavior. Journal of Marketing Education, 25(2), 130-142.

Zhao, J., \& Alexander, M. (2002). Information technology skills recommended for business students by fortune 500 executives. The Delta Pi Epsilon Journal, 44(3), 175-189.

\section{Appendix}

\section{A. Evaluation of Teaching Effectiveness Scale}

1 - Strongly Disagree; 2 - Disagree; 3 - Disagree Somewhat; 4 - Neither Agree Nor Disagree;

5 - Agree Somewhat; 6 - Agree; 7 - Strongly Agree

1. The course was well organized.

2. The instructor promoted discussion in class.

3. The instructor used media effectively.

4. The exam questions were clear and unambiguous.

5. The instructor was helpful and supportive.

6. I was satisfied with this course.

7. This course covered too much material.

8. The instructor struggled with the course material.

9. I learned a lot from this course.

10. The course objectives were clearly defined.

11. Instead of just listening to lectures, I was actively engaged in the learning process.

12. The media used in this course helped me learn.

13. The instructor provided help when asked. 
14. I had adequate time to complete course work.

15. I didn't learn much from this course.

16. The instructor returned graded assignments within a reasonable period.

17. The instructor was difficult to get along with.

18. The instructor is an expert in his/her field.

19. The course schedule changed so much that I was never sure what we were doing in class.

20. Assignments were unreasonably difficult.

21. The instructor treated students with respect.

22. Media were used in this course to effectively communicate course concepts.

23. The grading in this course was fair.

24. I was more of a participant in class than an observer.

25. The instructor was very knowledgeable.

26. The course was disorganized.

27. The media used in this course helped make the course interesting.

28. The instructor raised challenging questions for discussion in class.

\section{B. Learner Characteristics}

1. Please fill in your SAT mathematical score:

2. Number of mathematics courses taken to date:

3. Titles of mathematics courses taken to date:

4. Please fill in your cumulative grade point average (CGPA):

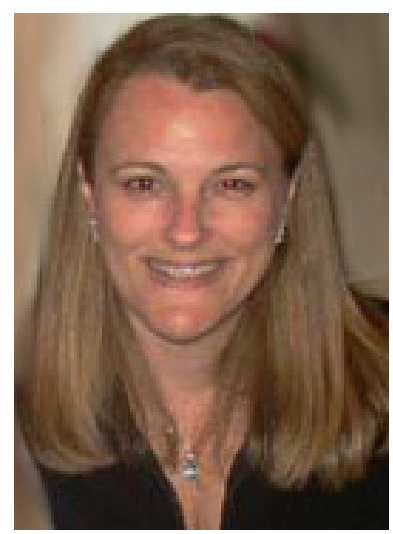

\section{Biography}

Nancy B. Sardone received her Ph.D. in Business Education from New York University (USA). She holds a Bachelor of Science degree from University of Massachusetts at Amherst in Resource Economics and a Master's in Business Education from New York University. She is currently an Assistant Professor in the Teacher Education Department at Georgian Court University, Lakewood, New Jersey. She teaches courses in instructional design and instructional technology for inclusive classrooms. Her research interests include curriculum, instruction, and technology integration in the teaching and learning process. Topics of published articles and presentations are assistive technologies, ePortfolios, digital learning games, virtual environments, and the development of IT fluency. 